\title{
Genetic differentiation in Sichuan jay (Perisoreus internigrans) and its sibling species Siberian jay (P. infaustus)
}

\author{
Kai Song ${ }^{1,2}\left(\right.$ D $\cdot$ Peter Halvarsson ${ }^{1,3} \cdot$ Yun Fang $^{2} \cdot$ Jonathan Barnaby $^{1} \cdot$ Nickolai Germogenov $^{4,5} \cdot$ Yuehua Sun $^{2}$. \\ Jacob Höglund ${ }^{1}$ (1)
}

Received: 2 October 2018 / Accepted: 23 January 2020 / Published online: 7 February 2020

(c) The Author(s) 2020

\begin{abstract}
The Pleistocene ice age and recent forest fragmentation have both played a significant role in shaping the population genetic variation of boreal coniferous species in the Qinghai-Tibet Plateau (QTP) and Eurasian coniferous forests. The Sichuan jay is one of the least know endemic bird species in QTP coniferous forests in western China while its sibling species, the Siberian Jay, is widespread within the coniferous forests in northern Eurasia. Here we used 11 microsatellite markers to assay genetic diversity across 58 Sichuan jay samples from China and 205 Siberian jay samples from Sweden and Russia. Results showed three distinct genetic clusters from the Sichuan jay sampling. Furthermore, the pair-wise $F_{S T}$ values indicated high genetic differentiation not only among the two species but also between Swedish and Russian Siberian jay populations. What is more, a pattern of isolation by distance was found among the analyzed populations. Our study suggests that targeted habitat restoration in fragmented forests and more genetic work is urgently needed for conservation of the Sichuan jay.
\end{abstract}

Keywords Coniferous forests $\cdot$ Microsatellites $\cdot$ Genetic differentiation $\cdot$ Sichuan jay $\cdot$ IBD

Electronic supplementary material The online version of this article (https://doi.org/10.1007/s10592-020-01252-y) contains supplementary material, which is available to authorized users.

Yuehua Sun

sunyh@ioz.ac.cn

$\triangle$ Jacob Höglund

Jacob.Hoglund@ebc.uu.se

1 Animal Ecology, Department of Ecology and Genetics, Uppsala University, Norbyvägen 18D, 75236 Uppsala, Sweden

2 Key Laboratory of Animal Ecology and Conservation Biology, Institute of Zoology, Chinese Academy of Sciences, Beijing 100101, People's Republic of China

3 Unit of Parasitology, Department of Biomedicine and Veterinary Public Health, Swedish University of Agricultural Sciences, PO Box 7036, 75007 Uppsala, Sweden

4 Department of Russian Academy for Sciences, Institute for Biological Problem of Cryolithozone Under Siberian, Yakutsk, Russia

5 North-East Federal University, Yakutsk, Russia

\section{Introduction}

Forest fragmentation has profound and lasting influences around the globe, not only on the Earth's biological diversity, but on ecosystem function and numerous ecosystem services (Kettle and Koh 2014; Pfeifer et al. 2017). At present, more and more large areas of continuous forests of the world are rapidly becoming fragmented by human influence, which apparently has negative ecological and genetic effects in the resulting forest patches for species that dwell in isolated forest islands (Haddad et al. 2015; Nason and Hamrick 1997; Robinson et al. 1995). Moreover, the direct ecological consequences of forest fragmentation include changing habitat connectivity, reducing species' richness, availability, and specialization (Bregman et al. 2014; Hadley et al. 2018; Hernando et al. 2017).

Fragmentation of continuous forests to become isolated patches can pose a long-term threat to populations and species through genetic bottlenecks, ecological traps, changing patterns of selection, inbreeding, drift, and gene flow, especially in the smallest and most isolated fragments (Bacles et al. 2005; Gaines et al. 1997; Höglund 2009; Orrock 2005; Templeton et al. 1990; Young et al. 1996). In addition to anthropogenic influence, mountain uplifts and 
past climatic changes have also caused forest fragmentation, which have resulted in isolation, divergence, and speciation in face of reduced gene flow in populations and species inhabiting such areas (Filatov et al. 2016; Rice and Hostert 1993). For example, the expanding ice sheets directly fragmented the boreal forest during recent glacial periods (Weir and Schluter 2004).

Speciation and divergence in boreal species promoted by natural causes are common in the coniferous forests of the Qinghai-Tibet Plateau (QTP), Northern Eurasia and North America (Hewitt 1996; Baba et al. 2002; Weir and Schluter 2004; Zhan et al. 2011). Although there is controversy about the role of the Quaternary ice ages in vertebrate speciation across the globe, the geographical distributions of some boreal species have indeed been fragmented periodically by habitat changes accompanying global cooling. This is related to the extent of boreal forest, which is a geographically extensive habitat zone and which was directly fragmented by advancing glaciers into multiple refugia (Avise 1998; Hewitt 2000, 2004; Zink and Slowinski 1995). There are several studies of genetic patterns in the northern boreal forest avifaunas in Europe and North America (Corrales et al. 2014; Höglund et al. 2013; Weir and Schluter 2004; Zhan et al. 2011). However, few studies have been conducted on sibling species in QTP and eastern and western Siberia, especially for those species that have poor dispersal capability (Lu et al. 2012a; Sun et al. 2001). Studies of this isolated avifauna should thus yield a greater understanding of the speciation into sibling species following fragmentation. During Pleistocene, many avian species living in boreal forest have evolved into superspecies or to different subspecies after they experienced allopatric divergence and local adaptation (Davis and Shaw 2001; Hewitt 2004; Li et al. 2013; Ren et al. 2017). High altitude boreal forests were preserved in the southeast edge of QTP by the uplift of QTP which comprise one of the key highaltitude biodiversity hotspots in the world (Myers et al. 2000). The evolutionary history and genetic diversity of the sibling species in QTP and Siberian boreal forests have not yet been fully examined.

In addition to ice ages affecting boreal fragmentation, more recent human actions, for instance, heavy deforestation, have exacerbated the fragmentation of boreal forest (Wallenius et al. 2010). The high-elevation coniferous forest, an important and special part of boreal forests, are located at the eastern and southern rim of QTP. This forest acts as a modern harbour for many rare species because of its relatively pristine state (Cincotta et al. 2000; Liu et al. 2009), such as Chinese grouse (Tetrastes sewerzowi) (Sun 2000), Blood pheasant (Ithaginis cruentus) (Jia et al. 2010) and Wild yak (Bos grunniens) (Ceballos et al. 1993). However, local species in this montane ecosystems are sensitive to the effects of human activity and climate change (Liu et al. 2009; Lyu and Sun 2014; Pounds et al. 1999).

The Sichuan Jay (Perisoreus internigrans) is one of the least known endemic bird species in western China and inhabits high mountain coniferous forests at an altitude between 2800 and $4500 \mathrm{~m}$. It is a sibling species to the Siberian jay ( $P$. infaustus) which inhabits boreal forest from Eastern Siberia to Fenno-Scandia in the west. The Sichuan jay has been recorded from only 17 locations in Gansu, Sichuan, Qinghai and Tibet (Fig. 1) (Jing 2005; Sun et al.
Fig. 1 Current distribution of Sichuan jay (Perisoreus internigrans) in southwest China (light gray), and Siberian jay (Perisoreus infaustus, dark gray), and the locations of sampling sites (black dots)

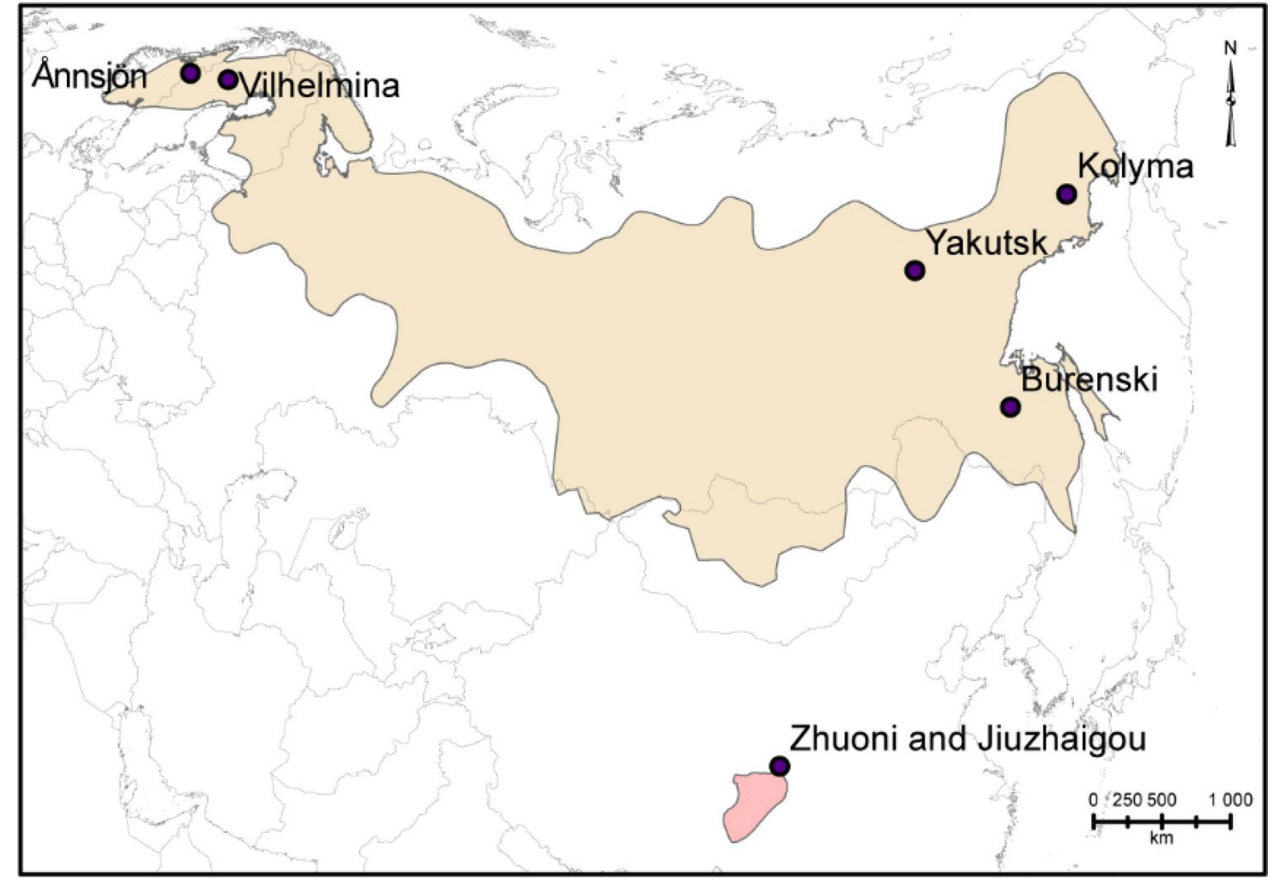


2001). The species is qualified as "Vulnerable" in IUCN's red list as it has a small, declining, severely fragmented populations as a result of extensive deforestation throughout its range (BirdLife International 2020). Despite the small and declining populations, it has not been put on the national protection list in China.

The first reliable survey of numbers and distribution was conducted from 1999-2004 in the forest areas in Zhuoni, Gansu $\left(34^{\circ} 14^{\prime}-34^{\circ} 38^{\prime} \mathrm{N} 103^{\circ} 12^{\prime}-103^{\circ} 32^{\prime} \mathrm{E}\right)$ and Jiuzhaigou, Sichuan $\left(33^{\circ} 31^{\prime}-33^{\circ} 7^{\prime} \mathrm{N} 103^{\circ} 39^{\prime}-103^{\circ} 46^{\prime} \mathrm{E}\right)$ (Yu et al. 2011). The two locations are about $120 \mathrm{~km}$ apart, and the forest areas are 20,000 and 16,000 ha, respectively. At the Zhuoni site, most of the old-growth spruce (Picea spp.) and fir (Abies spp.) were removed in selective cuts by the government in the 1930s and 1990s. At the Jiuzhaigou site, patches of pristine of forest alternate with clear-cut replanted areas (Sun et al. 2001). In these areas only a few small Sichuan jay populations were found, although the exact numbers of individuals were not obtained. Population density in Jiuzhaigou was about 1.04 per $\mathrm{km}^{2}$, and was even lower in Zhuoni (Yu et al. 2011). Until now, suitable Sichuan Jay habitat became increasingly fragmented from 1950s and very little was known regarding the genetics of this globally threatened montane bird (Jing et al. 2009; Lu et al. 2012b).

Here we use microsatellite allele frequencies to report: (1) genetic variation among endangered Sichuan jay populations; (2) compare levels of genetic diversity in the Sichuan jay population with Siberian jay populations from Siberia and Sweden; (3) estimate the effective population size and isolation by distance (IBD) of the Sichuan jay and Siberian jay; (4) a better understanding of the history and background data of this two sibling species, which could be used as a guideline for conservation of the Sichuan jay and Siberian jay and for other sibling species with similar characteristics.

\section{Methods}

\section{DNA samples}

In total, 58 Sichuan jay samples were obtained during 1999 to 2003 from China and 205 Siberian jay samples were collected during 2008 to 2010 from Sweden and Russia. For Sichuan jay samples, blood samples $(\mathrm{N}=30)$ and feather or muscle samples $(\mathrm{N}=28)$ from 58 captured jays and predation remains were collected in Sichuan and Gansu, western China (Fig. 1). Blood and muscle samples were stored in absolute ethanol in the field, and then stored long term at $-20^{\circ} \mathrm{C}$ in the lab. Feathers were stored dry at room temperature. DNA was extracted using a DNeasy ${ }^{\circledR}$ Tissue kit (QIAGEN, https://www.qiagen.com/) following the manufacturer's procedures. Siberian jay blood samples came from three populations in Russia Siberia (i.e. Burenski; Kolyma and Yakutsk) and from two populations in Sweden (i.e. Ånnsjön and Vilhelmina). DNA was extracted using a standard high salt extraction protocol modified from Paxton et al. (1996).

\section{Molecular methods}

Twenty one microsatellite loci originally developed for Siberian jay were amplified (Jaari et al. 2008) in both our Sichuan jay and Siberian jay samples. The microsatellite markers were divided into groups according to fluorescent dyes, which were FAM (SJ013, SJ014, SJ016, SJ026, SJ046, SJ049, SJ059, SJ068, SJ070, SJ078, SJ081, SJ083, SJ092, SJ093, SJ095, SJ106, SJ109, SJ116) and NED (SJ058, SJ065, SJ099). For the Sichuan jays, PCRs were run in $10 \mu \mathrm{L}$ reactions containing $0.20 \mu \mathrm{L}$ of each primer $(10 \mathrm{mM})$, $1.00 \mu \mathrm{L}$ of DNA, $1.00 \mu \mathrm{L} 10 \times$ PCR buffer, $0.50 \mu \mathrm{L}$ dNTPs $(2.5 \mathrm{mM}), 0.30 \mu \mathrm{L}$ BSA, $0.45 \mu \mathrm{L} \mathrm{MgCl} 2(25 \mathrm{mM}), 0.05 \mu \mathrm{L}$ DreamTaq and $6.50 \mu \mathrm{L}$ water. PCR programs were an initial denaturation cycle at $95^{\circ} \mathrm{C}$ for $3 \mathrm{~min}$, followed by 5 cycles at $95{ }^{\circ} \mathrm{C}$ for $30 \mathrm{~s}$, annealing at $59{ }^{\circ} \mathrm{C}$ to $54{ }^{\circ} \mathrm{C}$ for $30 \mathrm{~s}$ and $72{ }^{\circ} \mathrm{C}$ for $1 \mathrm{~min}$, then followed by 30 cycles at $95{ }^{\circ} \mathrm{C}$ for $30 \mathrm{~s}$, annealing at $54{ }^{\circ} \mathrm{C}$ for $30 \mathrm{~s}$ and $72{ }^{\circ} \mathrm{C}$ for $30 \mathrm{~s}$. The PCRs had a final extension at $72^{\circ} \mathrm{C}$ for $10 \mathrm{~min}$. The PCR products were diluted in water (1.1:10). $1 \mu \mathrm{l}$ of the dilution was mixed with $10 \mu \mathrm{l}$ formamid/ $\mathrm{H}_{2} \mathrm{O}$ containing $0.1 \mu \mathrm{l}$ GeneScanTM 600 LIZ $^{\circledR}$ size standard (Thermo Scientific) and run on 3730xl DNA Analyzer (Applied Biosystems). Samples were genotyped using GeneMapper ${ }^{\circledR}$ Software 5 (Life Technologies ${ }^{\mathrm{TM}}$ ). For the Siberian Jays, we amplified microsatellites makers using Qiagen multiplex mix according to the manufacturers' recommendations. Amplified products were diluted 1:100 with Megabace ET400-R as size standard prior to analysis on a Megabace 1000 (GE healthcare/Amersham) and genotyping was conducted using Megabace Fragment profiler 1.2 (GE healthcare/Amersham).

In total, 21 microsatellite loci amplified a PCR product giving genotypes for the 58 Sichuan jay samples. As SJ046 was found to be linked to the Z-chromosome, it was removed from further analyses. We used the Excel add-in Microsatellite toolkit to convert input microsatellite data files for different analyses program formats (Park 2001). All the microsatellite markers were analyzed with MICROCHECKER 2.2.3 (Van Oosterhout et al. 2004) to check for null alleles. Six out of 20 microsatellite loci (SJ013, SJ026, SJ065, SJ081, SJ083, and SJ092) were found to contain null alleles and were thus removed from further analyses. SJ014 and SJ059 were not available for Siberian jays. We tested for Hardy and Weinberg equilibrium and linkage disequilibria between molecular markers. To ensure the neutrality and independently segregating markers 
we discarded SJ016, SJ049 and SJ116. Thus, we used 11 microsatellite loci to analyze Sichuan jay samples. However, we used only 9 of the same microsatellite markers out of the previous 11 to analyze the Siberian jay samples due to lack of amplification concerning the makers SJ014 and SJ059.

\section{Statistical analysis}

We calculated expected heterozygosity $\left(\mathrm{H}_{\mathrm{e}}\right)$, observed heterozygosity $\left(\mathrm{H}_{\mathrm{o}}\right), \mathrm{F}_{\mathrm{IS}}$, allelic richness (AR), and effective population size $\left(\mathrm{N}_{\mathrm{e}}\right)$ in each of the sampled populations. The neutral genetic diversity for each locality was calculated in FSTAT 2.9.3.2 (Goudet 1995). Effective population size was estimated based on two different methods: the linkage disequilibrium method and the coancestry method using the software Ne estimator (Waples and Do 2008).

To illustrate the multidimensional relationships among individual Sichuan jays in a two-dimensional plot, we used the R package ADEGENET (Jombart 2008) to create discriminant analysis of principal components (DAPC) with 100,000 iterations and 10,000 burn-in steps. In addition we performed Bayesian clustering using STRUCTURE v.2.3.4 (Pritchard et al. 2000) to find genetic clusters among the all samples and for Sichuan jays excluding Siberian jays. The dataset was run ten times per $K=1-10$ with an initial burn-in of 10,000 followed by 100,000 MCMC iterations and 100,000 burn-in followed by 100,000 MCMC iterations for Sichuan jays only. Visualization of the runs was done using R package POPHELPER v2.2.9 (Francis 2017) after averaging over all STRUCTURE runs for each $K$ using CLUMPP (Jakobsson and Rosenberg 2007) included in the POPHELPER package.

To calculate population differentiation between the sampled locations, we used the data from the 9 microsatellite loci common to both species to calculate pair-wise $\mathrm{F}_{\mathrm{ST}}$ (Weir and Cockerham 1984) and Nei's genetic distance using SpaGeDi v1.5 (Hardy and Vekemans 2002). With their geographic coordinates, we calculated the Euclidean distance as the geographical distances. Then we used the geographical distance and $\mathrm{F}_{\mathrm{ST}} /\left(1-\mathrm{F}_{\mathrm{ST}}\right)$ to calculate the IBD in SpaGeDi v 1.5 (Hardy and Vekemans 2002).

Tests of past population bottlenecks were performed by calculating the difference between the expected heterozygosity under Hardy-Weinberg equilibrium $\left(H_{\mathrm{E}}\right)$ and the heterozygosity expected at mutation-drift equilibrium $\left(H_{\text {eq }}\right)$ assuming three different mutation models, the stepwise mutation model (SMM), two-phased models (TPM) and the infinite allele model (IAM), as implemented in software Bottleneck (Piry et al. 1999). We used Wilcoxon sign rank test to obtain $P$ values. The TPM was tested in different conditions with respect to the proportion of step-wise mutations (70, 60, 50, 40, 30, 20 and 10\%).

\section{Results}

\section{Genetic variation}

In the entire Sichuan jay population, expected heterozygosity $\left(\mathrm{H}_{\mathrm{e}}\right)$ was 0.741 , observed heterozygosity $\left(\mathrm{H}_{\mathrm{o}}\right)$ was 0.815 , and allelic richness (AR) was 3.25 (Table 1). We calculated a reliable value for $\mathrm{N}_{\mathrm{e}}$ by the linkage disequilibrium method $(\mathrm{Ne}(\mathrm{LDNe}))$ and by the coancestry method $(\mathrm{CNe})$. The estimates were: 16.1 (95\% CI 9.0 to 25.2 ) and 39.9 (95\% CI31.9 to 51.3), respectively (Table 1 ).

In Siberian jays, $\mathrm{H}_{\mathrm{e}}$ within the different populations ranged from 0.675 to $0.801, \mathrm{H}_{\mathrm{o}}$ from $0.627-0.750$ and allelic richness from 2.91 to 3.48 . Observed and expected heterozygosity were not significantly different, as would be expected of selectively neutral loci. Thus, based on the nine common microsatellites makers, we found heterozygosity and allelic richness to be of the same magnitude in both species. Our estimates of effective population size revealed similar values among the sampled populations with the exception of the Siberian jays in Kolyma which showed a significantly higher estimate (Table 1).

Table 1 Genetic variation in endangered $P$. internigrans (11 microsatellites) and non-threatened $P$. infaustus ( 9 microsatellites) populations

\begin{tabular}{lllllllll}
\hline Species & Location & $\mathrm{n}$ & $\mathrm{H}_{\mathrm{e}}$ & $\mathrm{H}_{\mathrm{o}}$ & $\mathrm{F}_{\mathrm{is}}$ & $\mathrm{AR}$ & $\mathrm{N}_{\mathrm{e}}\left(\mathrm{CN}_{\mathrm{e}}, 95 \% \mathrm{CI}\right)$ & $\mathrm{Ne}(\mathrm{LDN}$,, $95 \% \mathrm{CI})$ \\
\hline Sichuan jay & Sichuan, China & 58 & 0.741 & 0.815 & -0.101 & 3.25 & $16.1(9.0-25.2)$ & $39.9(31.9-53.3)$ \\
Siberian jay & Ånnsjön, Sweden & 37 & 0.731 & 0.750 & -0.026 & 3.09 & $14.4(4.7-29.5)$ & $31.6(22.6-47.6)$ \\
& Vilhelmina, Sweden & 41 & 0.737 & 0.733 & 0.006 & 3.15 & $\operatorname{Inf}(\operatorname{Inf}-\mathrm{Inf})$ & $64.9(42.0-123.3)$ \\
& Burenski, Russia & 31 & 0.759 & 0.711 & 0.064 & 3.28 & $21.7(3.6-55.7)$ & $42.5(29.6-69.3)$ \\
& Kolyma, Russia & 18 & 0.675 & 0.627 & 0.075 & 2.91 & $1517.6(1.5-7615.3)$ & $14.3(9.2-24.6)$ \\
& Yakutsk, Russia & 78 & 0.801 & 0.740 & 0.076 & 3.48 & $28.8(10.0-57.4)$ & $110.7(84.2-155.5)$ \\
\hline
\end{tabular}

$n$, number of individuals; $\mathrm{H}_{\mathrm{e}}$, expected heterozygosity, $\mathrm{H}_{\mathrm{o}}$, observed heterozygosity; $\mathrm{F}_{\mathrm{is}}$, inbreeding coefficient in populations; AR, allelic richness; $\mathrm{N}_{\mathrm{e}}$, effective population size by coancestry method $\left(\mathrm{Ne}\left(\mathrm{CN}_{\mathrm{e}}\right)\right)$ and by linkagedisequilibrium method $\left(\mathrm{LDN}_{\mathrm{e}}\right)$ 
Fig. 2 Discriminant analysis of principle components (DAPC) scatterplot. The three DAPC clusters are based on 11 microsatellite makers from $58 P$. infaustus from Sichuan, China

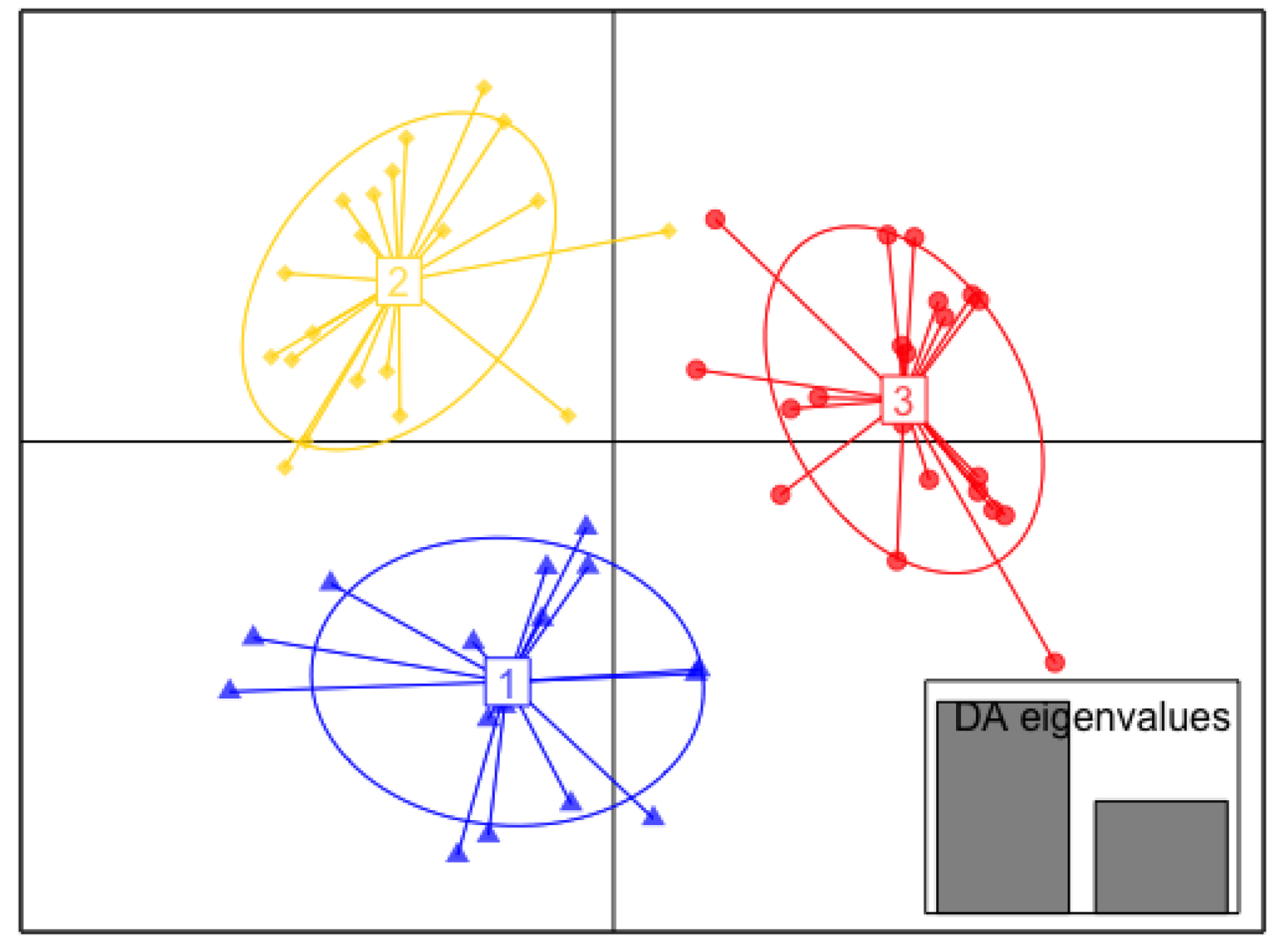

\section{Population differentiation}

Geographic structure and separation among the sampled Sichuan jay was supported by the discriminant analysis of principle components (DAPC) (Fig. 2) which shows three main clusters among the Chinese samples based on the Bayesian Information Criterion. These results were confirmed by STRUCTURE analyses which support three weakly differentiated clusters when sorted by assignment probability (Q) (Suppl. Fig. 1). For all jay samples, three distinct clusters was found in the STRUCTURE analysis (Suppl. Fig. 2), supported by the Evanno method (Evanno et al. 2005) that gave the highest support for $K=3$ (delta-K) (Suppl. Fig. 3). The three clusters followed country of sampling.

Pair-wise $F_{S T}$ values ranged between 0.026 and 0.52 when all populations and both species were included in the analysis (Table 2). As expected, the highest $F_{S T}$ values were found between Sichuan jays and Siberian jay populations as they belong to different species. With the exception of the
Kolyma-Sichuan comparison the overall $F_{S T}$ were not much higher than the comparison between Swedish and Russian Siberian jay populations. In contrast, the within region comparisons in Sweden and Russia had the lowest values and comparisons between these regions had the highest $F_{S T}$ values respectively. Nei's genetic distance values had the same trend as the $F_{S T}$ values (Table 2). The lowest values were found between the two sampled locations from Sweden and three sampled locations from Russia. The highest values were found between Sichuan jays and Siberian jays (Table 2).

A highly significant correlation was found between genetic differentiation and geographic distance of populations when all populations were included in the IBD analyses $\left(r^{2}=0.5113, P<0.001\right.$; Fig. 3$)$. When IBD analysis was run only on Siberian jay populations, the correlation was also highly significant $\left(\mathrm{r}^{2}=0.8568, P<0.001\right.$; Fig. 3$)$.
Table 2 Location pairwise $F_{\mathrm{ST}}$ values (below the diagonal) and Nei's genetic distance (Ds) (above the diagonal) for $P$. internigrans and $P$. infaustus

\begin{tabular}{lllllll}
\hline ALL LOCI & Sichuan & Ånnsjön & Vilhelmina & Burenski & Kolyma & Yakutsk \\
\hline Sichuan & & 2.212 & 2.146 & 1.768 & 1.872 & 2.031 \\
Ånnsjön & 0.240 & & 0.088 & 0.705 & 0.734 & 0.586 \\
Vilhelmina & 0.238 & 0.030 & & 0.718 & 0.714 & 0.599 \\
Burenski & 0.214 & 0.148 & 0.147 & & 0.293 & 0.102 \\
Kolyma & 0.52 & 0.178 & 0.173 & 0.090 & & 0.161 \\
Yakutsk & 0.201 & 0.119 & 0.118 & 0.026 & 0.052 & \\
\hline
\end{tabular}


Fig. 3 Isolation by distance plots (IBD) for microsatellite data. $F_{\mathrm{ST}} /\left(1-F_{\mathrm{ST}}\right)$ is a function of distance $(\mathrm{km})$. Black squares: IBD for pair-wise population comparisons of 263 individuals of $P$. internigrans and $P$. infaustus. Black circles: IBD based on 205 individuals of $P$. infaustus. The $\mathrm{r}^{2}$ represents the coefficient of determination and $P$ the probability value. The dashed line: the trend curve for all jays; The dots line: the trend curve for Siberian jays

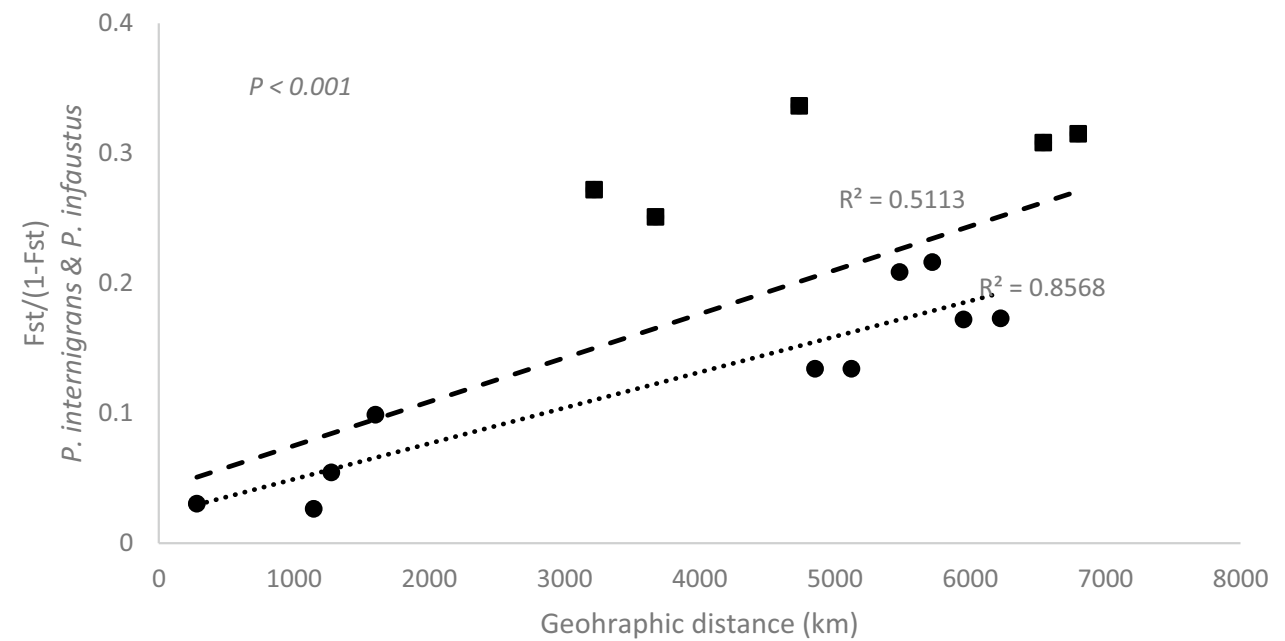

Table 3 Results of the test for a population bottleneck

\begin{tabular}{|c|c|c|c|c|c|c|c|}
\hline \multirow[t]{2}{*}{ Mutation Model } & \multirow{2}{*}{$\begin{array}{l}\text { Proportion of } \\
\text { SMM }(\%)\end{array}$} & \multicolumn{6}{|c|}{ One-tailed Wilcoxson test for heterozygote excess } \\
\hline & & Sichuan & Ånnsjön & Vilhelmina & Burenski & Kolyma & Yakutsk \\
\hline SMM & & $P=0.051^{\mathrm{NS}}$ & $P=0.285^{\mathrm{NS}}$ & $P=0.102^{\mathrm{NS}}$ & $P=0.180^{\mathrm{NS}}$ & $P=0.010$ & $P=0.715^{\mathrm{NS}}$ \\
\hline TPM & 70 (default) & $P=0.005^{*} *$ & $P=0.010^{*}$ & $P=0.002 * *$ & $P=0.003^{* *}$ & $P=0.001 * *$ & $P=0.024^{*}$ \\
\hline TPM & 60 & $P=0.002^{*} *$ & $P=0.005^{* *}$ & $P=0.001 * *$ & $P=0.002 * *$ & $P=0.001 * *$ & $P=0.005^{* *}$ \\
\hline TPM & 50 & $P=0.002^{* *}$ & $P=0.005^{* *}$ & $P=0.001 * *$ & $P=0.002 * *$ & $P=0.001 * *$ & $P=0.003^{* *}$ \\
\hline ТPM & 40 & $P=0.001^{* *}$ & $P=0.003^{* *}$ & $P=0.001 * *$ & $P=0.001 * *$ & $P=0.001 * *$ & $P=0.002^{*} *$ \\
\hline TPM & 30 & $P=0.001^{* *}$ & $P=0.003^{* *}$ & $P=0.001 * *$ & $P=0.001 * *$ & $P=0.001 * *$ & $P=0.002^{* *}$ \\
\hline TPM & 20 & $P=0.001^{*} *$ & $P=0.003 * *$ & $P=0.001 * *$ & $P=0.001 * *$ & $P=0.001 * *$ & $P=0.002^{*} *$ \\
\hline TPM & 10 & $P=0.001^{* *}$ & $P=0.003^{* *}$ & $P=0.001 * *$ & $P=0.001^{* *}$ & $P=0.001 * *$ & $P=0.002^{* *}$ \\
\hline IAM & & $P=0.001^{* *}$ & $P=0.002 * *$ & $P=0.001 * *$ & $P=0.001 * *$ & $P=0.001^{* *}$ & $P=0.002^{*} *$ \\
\hline
\end{tabular}

$S M M$ stepwise mutation model, TPM two-phased model, IAM infinite allele model

NS not significant; $* 0.01<P<0.05 ; * * 0.001<P<0.01$

\section{Analyses of population bottlenecks}

We found evidence of mutation-drift heterozygote excess (Heq) according to a one-tailed Wilcoxson test for heterozygote excess in all populations, except when assuming a strict SMM (Table 3). We therefore conclude that there is a strong indication of past population bottlenecks in both species.

\section{Discussion}

The results of this study show that the Sichuan jay, which inhabit a narrow band of fragmented high-elevation coniferous forests, has similar levels of genetic variability as compared to the Siberian jay since estimates of genetic diversity were similar when comparing values of AR, $\mathrm{Ho}$ and He. These sister species formed after the rise of QTP during the Quaternary Period (Cheng 1981) as some other sibling species pairs which like jays have a similar distribution pattern, such as the Chinese grouse and hazel grouse ( $T$. bonasia). That estimates of genetic diversity in Sichuan and Siberian jay populations are similar is somewhat surprising as we would have expected lower diversity in the more range restricted Sichuan jay.

The distribution and genetic diversity of species are important for their conservation, especially for relict populations in isolated refugia (Höglund 2009). As the first study describing the genetic diversity of Sichuan jay, the discriminant analysis revealed genetic differentiation among Sichuan jay samples (Fig. 2). Unfortunately the $\mathrm{x}-\mathrm{y}$ coordinates of the Sichuan jay samples have been lost since the date of capture and we can thus not test if the detected substructure is due to geographically separated populations. However, as a proxy of gene flow rupture, the observed genetic differentiation confirm previous results showing that remaining Sichuan jay habitats are at present isolated and fragmented because of intensive 
forest cutting of the virgin forest during the past decades (Lu et al. 2012b; Sun 2000).

$\mathrm{N}_{\mathrm{e}}$ is one of the most important parameters in conservation genetics and could be regarded as an estimate of genetic diversity since it corresponds to the heterozygosity in an ideal randomly mating population with the estimated size. A low $\mathrm{N}_{\mathrm{e}}$ value is also associated with accelerated depletion of genetic variability (Hájková et al. 2007). In all these six populations, including both sub species, our estimates of $\mathrm{N}_{\mathrm{e}}$ from two methods provided reliable values except for Kolyma which had a value reaching infinity using the $\mathrm{CNe}$ method, which is indicative of a too small sample size. The $\mathrm{N}_{\mathrm{e}} / \mathrm{N}$ ratio in wild populations is approximately estimated to be in the range of 0.10 (Frankham 1995). This estimate would for Sichuan jay in Sichuan give a population size of 162 and 399 individuals which is close to the range of 132 to 374 given by our census data from 2000 to 2004 (Jing 2005).

The pairwise $F_{S T}$ and Nei's genetic distance (Ds) analyses showed the highest $F_{S T}$ values and Ds values between Sichuan and Siberian jay populations, and also showed high values when comparing populations from Sweden with Russia. Nei's genetic distance analysis showed a strong divergence among the two species. The Sichuan jay population was separated from the five Siberian populations. Correspondingly there were high $F_{S T}$ values among Swedish and Russian populations. Such genetic differentiation between QTP coniferous forest species and sister taxa residing in coniferous forest in northern Eurasia are common in other animals and insects confined to boreal forest (Baba et al. 2002; Johansson et al. 2017). For a conservation perspective, preserving boreal forest surrounding the QTP would also benefit the QTP-residing species of avina genera such as: Tetrastes, Strix, Aegolius and Picoides.

Our results indicate that IBD pattern was found not only in the total locations of Sichuan jay and Siberian jay, but also among Swedish and Russian locations of the Siberian jay (Fig. 3). This IBD pattern may be influenced by the fragmentation of boreal forest which was affected by the last ice age and recent human actions (Wallenius et al. 2010). The described situation should be similar in other boreal birds in Siberia and the QTP. Some studies have suggested that many of these populations, like hazel grouse, might come from one or a few refugial lineages from central and western coniferous forest in Eurasia, which might have been almost completely eradicated during the major glaciations (Baba et al. 2002; Englbrecht et al. 2000). The divergence and speciation in the boreal avifauna during this period resulted in some becoming sister-species, like the two jays studied here and some becoming subspecies like in boreal owl Aegolius funereus (Weir and Schluter 2004). Their dispersal abilities and response to the ice age and subsequent warming correspond to their divergence and speciation (Barluenga and Meyer 2005; Hewitt 1999). Large-scale comparative population genetic studies of sister-species, like Sichuan jay and Siberian jay, of boreal coniferous forest would provide a comprehensive view of the genetic consequences of the glaciation events on species with different life histories, and their effect on the current genetic diversity and geographical distribution patterns. Due to the glaciation events in the ancient and recent human actions, boreal forests became fragmented and isolated (Wallenius et al. 2010). Thus, we hypothesize that the jay populations of Sichuan and Siberia have experienced bottleneck as a result of habitat loss that likely occurred during glacial period and/ or more recently as a result human disturbances.

Habitat loss is the most important cause of species extinction (IUCN 2020). In order to maintain healthy populations of Sichuan jay in western China, targeted habitat restoration is important which can reduce extinction rates in fragmented forests (Newmark et al. 2017). To prevent nest predation, that is the most common cause of nest failure in Siberian jays, they need to nest in virgin conifer forest for sucessful breeding (Eggers et al. 2005; Griesser and Nystrand 2009). As both species are expected to have similar breeding ecology and need prestine forest for sucessful breeding, it is of utter importance for the recrutiment of new individuals to the population, we therefore suggest that more attention should be paid to the protection of virgin conifer forest in western China. This will benefit not only the Sichuan jay, but also many other rare species distributed in the same area, such as Chinese grouse, Boreal owl, Sichuan Wood Owl, and blood pheasant. There is also an urgent need to study other populations of Sichuan jay in China and central Russian populations of Siberian jay not included in this study, to better understand the conservation value, needs and importance of each population.

Acknowledgements Open access funding provided by Uppsala University. Thanks to Yu Jing, Rebecka Lindbom, the Strandberg family, Ülo Väli and Magnus Johansson for the help in field, to Gunilla Engström and Maria Cortazar for the help in lab. Funding was provided by National Natural Science Foundation of China (NSFC: 31520103903 to SYH, KS), Olsson-Borghs stiftelse (to PH), Stiftelsen för Zoologisk forskning (To PH, JB, KS).

Open Access This article is licensed under a Creative Commons Attribution 4.0 International License, which permits use, sharing, adaptation, distribution and reproduction in any medium or format, as long as you give appropriate credit to the original author(s) and the source, provide a link to the Creative Commons licence, and indicate if changes were made. The images or other third party material in this article are included in the article's Creative Commons licence, unless indicated otherwise in a credit line to the material. If material is not included in the article's Creative Commons licence and your intended use is not permitted by statutory regulation or exceeds the permitted use, you will need to obtain permission directly from the copyright holder. To view a copy of this licence, visit http://creativecommons .org/licenses/by/4.0/. 


\section{References}

Avise JC (1998) Pleistocene phylogeographic effects on avian populations and the speciation process. Proc R Soc Lond B 265:457-463

Baba Y, Fujimaki Y, Klaus S, Butorina O, Drovetskii S, Koike H (2002) Molecular population phylogeny of the hazel grouse Bonasa bonasia in East Asia inferred from mitochondrial controlregion sequences. Wildl Biol 8:251-260

Bacles CF, Burczyk J, Lowe AJ, Ennos RA (2005) Historical and contemporary mating patterns in remnant populations of the forest tree Fraxinus excelsior L. Evolution 59:979-990

Barluenga M, Meyer A (2005) Old fish in a young lake: stone loach (Pisces: Barbatula barbatula) populations in Lake Constance are genetically isolated by distance. Mol Ecol 14:1229-1239

BirdLife International (2020) Species factsheet: Perisoreus internigrans. https://www.birdlife.org/ Accessed on 7 Feb 2020

Bregman TP, Sekercioglu CH, Tobias JA (2014) Global patterns and predictors of bird species responses to forest fragmentation: implications for ecosystem function and conservation. Biol Conserv 169:372-383

Ceballos G, Mellink E, Hanebury LR (1993) Distribution and conservation status of prairie dogs Cynomys mexicanus and Cynomys ludovicianus in Mexico. Biol Conserv 63:105-112

Cheng T-S (1981) The fauna and its evolution of territorial vertebrates at Qinghai-Tibet plateau. Rep Beijing Natl Mus 9:1-17

Cincotta RP, Wisnewski J, Engelman R (2000) Human population in the biodiversity hotspots. Nature 404:990

Corrales C, Pavlovska M, Höglund J (2014) Phylogeography and subspecies status of Black Grouse. J Ornithol 155:13-25

Davis MB, Shaw RG (2001) Range shifts and adaptive responses to quaternary climate change. Science 292:673-679

Eggers S, Griesser M, Andersson T, Ekman J (2005) Nest predation and habitat change interact to influence Siberian jay numbers. Oikos 111(1):150-158

Englbrecht C, Freyhof J, Nolte A, Rassmann K, Schliewen U, Tautz D (2000) Phylogeography of the bullhead Cottus gobio (Pisces: Teleostei: Cottidae) suggests a pre-Pleistocene origin of the major central European populations. Mol Ecol 9:709-722

Evanno G, Regnaut S, Goudet J (2005) Detecting the number of clusters of individuals using the software STRUCTURE: a simulation study. Mol Ecol 14:2611-2620

Filatov DA, Osborne OG, Papadopulos AS (2016) Demographic history of speciation in a Senecio altitudinal hybrid zone on Mt. Etna. Mol Ecol 25:2467-2481

Francis RM (2017) Pophelper: an R package and web app to analyse and visualize population structure. Mol Ecol Resour 17:27-32. https://doi.org/10.1111/1755-0998.12509

Frankham R (1995) Conservation genetics. Annu Rev Genet 29:305-327

Gaines M, Diffendorfer J, Tamarin R, Whittam T (1997) The effects of habitat fragmentation on the genetic structure of small mammal populations. J Hered 88:294-304

Goudet J (1995) FSTAT (version 1.2): a computer program to calculate F-statistics. J Hered 86:485-486

Griesser M, Nystrand M (2009) Vigilance and predation of a forestliving bird species depend on large-scale habitat structure. Behav Ecol 20(4):709-715

Haddad NM et al (2015) Habitat fragmentation and its lasting impact on Earth's ecosystems. Sci Adv 1:e1500052

Hadley AS, Frey SJ, Robinson WD, Betts MG (2018) Forest fragmentation and loss reduce richness, availability, and specialization in tropical hummingbird communities. Biotropica 50:74-83
Hájková P, Pertoldi C, Zemanová B, Roche K, Hajek B, Bryja J, Zima J (2007) Genetic structure and evidence for recent population decline in Eurasian otter populations in the Czech and Slovak Republics: implications for conservation. J Zool 272(1):1-9

Hardy OJ, Vekemans X (2002) SPAGeDi: a versatile computer program to analyse spatial genetic structure at the individual or population levels. Mol Ecol Resour 2:618-620

Hernando A, Velázquez J, Valbuena R, Legrand M, García-Abril A (2017) Influence of the resolution of forest cover maps in evaluating fragmentation and connectivity to assess habitat conservation status. Ecol Ind 79:295-302

Hewitt GM (1996) Some genetic consequences of ice ages, and their role in divergence and speciation. Biol J Lin Soc 58(3):247-276

Hewitt GM (1999) Post-glacial re-colonization of European biota. Biol $\mathrm{J}$ Lin Soc 68:87-112

Hewitt G (2000) The genetic legacy of the quaternary ice ages. Nature 405:907

Hewitt G (2004) Genetic consequences of climatic oscillations in the quaternary. Philos Trans R Soc B 359:183-195

Höglund J (2009) Evolutionary conservation genetics. Oxford University Press, New York

Höglund J, Wang B, Axelsson T, Quintela M (2013) Phylogeography of willow grouse (Lagopus lagopus) in the Arctic: taxonomic discordance as inferred from molecular data. Biol J Lin Soc 110:77-90

IUCN (2020) The IUCN red list of threatened species. Version 2019-3. https://www.iucnredlist.org.

Jaari S, Välimäki K, Merilä J (2008) Isolation and characterization of 100 polymorphic microsatellite loci for the Siberian jay (Perisoreus infaustus). Mol Ecol Resour 8:1469-1474

Jakobsson M, Rosenberg NA (2007) CLUMPP: a cluster matching and permutation program for dealing with label switching and multimodality in analysis of population structure. Bioinformatics 23:1801-1806

Jia C-X, Sun Y-H, Swenson JE (2010) Unusual incubation behavior and embryonic tolerance of hypothermia by the Blood Pheasant (Ithaginis cruentus). Auk 127:926-931

Jing Y (2005) Life history, cooperative breeding, foraging competition and distribution of Sichuan jay (Perisoreus internigrans). Institute of Zoology, Chinese Academy of Sciences, Beijing

Jing Y, Fang Y, Strickland D, Lu N, Sun Y-H (2009) Alloparenting in the rare Sichuan jay (Perisoreus internigrans). Condor 111:662-667

Johansson F, Halvarsson P, Mikolajewski D, Höglund J (2017) Genetic differentiation in the boreal dragonfly Leucorrhinia dubia in the Palearctic region. Biol J Lin Soc 121:294-304

Jombart T (2008) adegenet: a R package for the multivariate analysis of genetic markers. Bioinformatics 24:1403-1405

Kettle CJ, Koh LP (2014) Global forest fragmentation. CABI, Wallingford. https://doi.org/10.1079/9781780642031.0050

Li L et al (2013) Pliocene intraspecific divergence and Plio-Pleistocene range expansions within Picea likiangensis (Lijiang spruce), a dominant forest tree of the Qinghai-Tibet Plateau. Mol Ecol 22:5237-5255

Liu $\mathrm{Z}$ et al (2009) The effect of landscape features on population genetic structure in Yunnan snub-nosed monkeys (Rhinopithecus bieti) implies an anthropogenic genetic discontinuity. Mol Ecol 18:3831-3846

Lu N, Jia C-X, Lloyd H, Sun Y-H (2012a) Species-specific habitat fragmentation assessment, considering the ecological niche requirements and dispersal capability. Biol Conserv 152:102-109

Lu N, Jing Y, Lloyd H, Sun Y-H (2012b) Assessing the distributions and potential risks from climate change for the Sichuan jay (Perisoreus internigrans). Condor 114:365-376 
Lyu N, Sun Y-H (2014) Predicting threat of climate change to the Chinese grouse on the Qinghai-Tibet plateau. Wildl Biol 20:73-82

Myers N, Mittermeier RA, Mittermeier CG, Da Fonseca GA, Kent J (2000) Biodiversity hotspots for conservation priorities. Nature 403:853

Nason J, Hamrick J (1997) Reproductive and genetic consequences of forest fragmentation: two case studies of neotropical canopy trees. J Hered 88:264-276

Newmark WD, Jenkins CN, Pimm SL, McNeally PB, Halley JM (2017) Targeted habitat restoration can reduce extinction rates in fragmented forests. Proc Natl Acad Sci 114:9635-9640

Orrock JL (2005) Conservation corridors affect the fixation of novel alleles. Conserv Genet 6:623-630

Park S (2001) The Excel microsatellite toolkit trypanotolerance in West African Cattle and the population genetic effects of selection

Paxton RJ, Thorén PA, Tengö J, Pamilo P (1996) Mating structure and nestmate relatedness in a communal bee, Andrena jacobi (Hymenoptera, Andrenidae), using microsatellites. Mol Ecol 5(4):511-519

Pfeifer M et al (2017) Creation of forest edges has a global impact on forest vertebrates. Nature 551:187

Piry S, Luikart G, Cornuet JM (1999) BOTTLENECK: a computer program for detecting recent reductions in the effective population size using allele frequency data. J Hered 90:502-503

Pounds JA, Fogden MP, Campbell JH (1999) Biological response to climate change on a tropical mountain. Nature 398:611

Pritchard JK, Stephens M, Donnelly P (2000) Inference of population structure using multilocus genotype data. Genetics 155:945-959

Ren G et al (2017) Genetic consequences of quaternary climatic oscillations in the Himalayas: Primula tibetica as a case study based on restriction site-associated DNA sequencing. New Phytol 213:1500-1512

Rice WR, Hostert EE (1993) Laboratory experiments on speciation: what have we learned in 40 years? Evolution 47:1637-1653

Robinson SK, Thompson FR III, Donovan TM, Whitehead DR, Faaborg J (1995) Regional forest fragmentation and the nesting success of migratory birds. Science 267:1987
Sun Y-H (2000) Distribution and status of the Chinese grouse Bonasa sewerzowi. Wildl Biol 6:271-275

Sun YH, Jia CX, Fang Y (2001) The distribution and status of Sichuan Grey Jay (Perisoreus internigrans). J Ornithol 142:93-98

Templeton AR, Shaw K, Routman E, Davis SK (1990) The genetic consequences of habitat fragmentation. Ann Mo Bot Gard 77:13-27

Van Oosterhout C, Hutchinson WF, Wills DP, Shipley P (2004) MICRO-CHECKER: software for identifying and correcting genotyping errors in microsatellite data. Mol Ecol Resour 4:535-538

Wallenius $\mathrm{T}$ et al (2010) Loss of habitats, naturalness and species diversity in Eurasian forest landscapes. Ecol Ind 10:1093-1101

Waples RS, Do C (2008) LDNE: a program for estimating effective population size from data on linkage disequilibrium. Mol Ecol Resour 8:753-756

Weir BS, Cockerham CC (1984) Estimating F-statistics for the analysis of population structure. Evolution 38:1358-1370

Weir JT, Schluter D (2004) Ice sheets promote speciation in boreal birds. Proc R Soc Lond B 271:1881-1887

Young A, Boyle T, Brown T (1996) The population genetic consequences of habitat fragmentation for plants. Trends Ecol Evol 11:413-418

Yu J, Lü N, Yun F, Yue-Hua S (2011) Home range, population density, and habitat utilization of the Sichuan jay (Perisoreus internigrans). Chin Birds 2:94-100

Zhan X, Zheng Y, Wei F, Bruford MW, Jia C (2011) Molecular evidence for Pleistocene refugia at the eastern edge of the Tibetan Plateau. Mol Ecol 20:3014-3026

Zink RM, Slowinski JB (1995) Evidence from molecular systematics for decreased avian diversification in the Pleistocene epoch. Proc Natl Acad Sci 92:5832-5835

Publisher's Note Springer Nature remains neutral with regard to jurisdictional claims in published maps and institutional affiliations. 